\title{
Application of Design Thinking for Requirements Elicitation in Mobile Applications
}

\author{
Edna Dias Canedo \\ University of Brasília (UnB) \\ Brasília, DF, Brazil \\ ednacanedo@unb.br \\ Anderson Jefferson Cerqueira \\ University of Brasília (UnB) \\ Brasília, DF, Brazil \\ andersonjcdf@gmail.com
}

Alexandre V. Papadópolis

University of Brasília (UnB)

Brasília, DF, Brazil

alex@sbpi.com.br

\author{
Aleteia Patricia F.de Araujo \\ University of Brasília (UnB) \\ Brasília, DF, Brazil \\ aleteia@unb.br
}

\begin{abstract}
Design Thinking has been used by organizations as a requirement elicitation technique for making use of the immersion procedure that, as a consequence, brings the team stakeholder closer to the software project and allows the creation of projects with a design that is closer to the end user and with higher quality, minimizing the problems in requirements elicitation. In this work, we evaluate the elicitation process of software requirements of mobile applications developed in a Brazilian Public Agency using Design Thinking. Furthermore, we presented a practical case study in which Design Thinking is used in eliciting requirements of developed applications. We also compared the phases of development process adopted by the Agency with the Design thinking recommendations. Our comparative study demonstrates that the traditional methodology adopted by the Agency is bureaucratic and hinders the creation process, as well as the interaction between stakeholders and members of the development team and the transfer of knowledge.
\end{abstract}

\section{Introduction}

Software requirements are the prediction of customers expressed in relation to software quality, which distinguish services, constraints and characteristics of the system must be, obey and have, and specify the necessary knowledge to be developed [1]. It is obtained through a systematic process involving various tasks, such as elicitation, analysis and negotiation, as well as documentation, validation and requirements management.

Eliciting proper requirements in a software project is considered one of the most important and difficult activities of the system development process. The deficiency in this treatment of requirements has been pointed out as the main cause of failure of software projects [2]. Given this, Design Thinking emerges as a method that gathers design-inspired practices for project resolution and development, using empathy, encouraging creativity and rationality to meet users' needs and converge to innovative solutions [3].

Since 2013, the Department of Information Technology of the National Health System (DATASUS) of the Ministry of Health (MS), has invested in solutions compatible with smartphones and tablets to deliver innovative digital services that promote citizen engagement in an integrated way to existing corporate systems at the MS. The agile application development cycle enables the government to create rapid responses to the needs of citizens and organizations. By understanding the usefulness of mobile applications, the MS can deliver value to society with greater efficiency, agility, and innovation. However, in order for mobile solutions to transform the digital services of the Brazilian Unified Health System (SUS) and become an integral part of Brazilian citizens' lives, they must meet the complex requirements imposed by the health sector, as well as those which are typical of the SUS user profile, formed by all social classes, levels of instruction and fluency in the use of mobile devices.

Design Thinking enables a user-centric requirement elicitation that, through interaction among all involved parts, enables the creation of solutions that meet both individual and business needs. This property, in a context of Information and Communications Technology Governance as complex as Brazilian public health, makes Design Thinking an appropriate approach for the construction of effective information products. Therefore, our objective with this work is to investigate how Design Thinking is being used by software development teams in DATASUS and how knowledge transfer is carried out between the participant teams. This analysis will allow an evaluation of the processes adopted by the development teams that adopt Design Thinking in eliciting the requirements of the products developed by the organization, allowing them to make improvements in the adopted processes. To achieve this goal, we have defined the following research questions:

RQ.1: What is the degree of adherence between the 
requirements elicitation process for DATASUS mobile applications and Design Thinking?

RQ.2: Was the transfer of knowledge between the software development teams using Design Thinking and the teams using the traditional process adequate and did it meet expectations?

In order to respond the main objective of this work, we conducted a practical case study using the DATASUS software development process and Design Thinking. We compared the results with the traditional process, previously conducted by the MS software development process.

The main contribution of this work was to identify the advantages of the use of Design Thinking in the elicitation of the requirements of the mobile applications development. The Design Thinking methodology allowed greater interaction between the development team and Stakeholders, being able to be adopted as a technique for surveying the needs of citizens and bringing them, closer to the application.

\section{Background and Related Works}

The requirements elicitation process consists of five activities, namely: Elicitation, analysis and negotiation, documentation, verification and validation and project management [4]. A thorough understanding of software requirements is critical to successful development, which is a constant need of all participants. No matter how projected or coded it is, a poorly analyzed and specified system will disappoint the user and annoy the stakeholders and the development team [5].

According to the literature, the main flaws in software projects are related to requirements elicitation. These failures are due to difficulties in understanding user needs, poorly described or incomplete requirements and uncontrolled changes of requirements. According to [6], in the requirements elicitation activity, teams work with stakeholders to learn more about the application domain, the services that the system must provide, operational constraints, and performance required (non-functional requirements). Moreover, the success of software projects depends, among other things, on the skills of the team members [7]. However, the selection and combination of different team members is an ongoing challenge [8].

The complexity of requirements elicitation involves not only negotiation skills but also creativity [9]. Previous studies have found that heterogeneity among the team members increases creativity [7]. At the same time, the heterogeneity of team members' attributes, namely, creativity, productivity, knowledge transfer, communication, negotiation, among others, can also lead to the formation of subgroups within the project team. Especially software projects which apply agile methods, like Scrum or Extreme Programming demand team heterogeneity and foster close collaboration [10]. Otherwise, teams that follow traditional project management methods are selected based on their capabilities to conduct a pre-planned task [11]. Design Thinking leverages this heterogeneity of team members in requirements elicitation.

\subsection{Design Thinking}

Design Thinking, as an approach to innovation and business challenges, is currently attracting a large (and increasing) amount of interest in both management practice as well as academic literature [12]. Design Thinking is being used because the literature argues that it is useful for a range of business challenges, particularly those involving high complexity such as elicitation requirements problems. The elicitation of requirements lacks both definite formulations and solutions, and faces high levels of uncertainty [12]. Design Thinking is a term that has grown exponentially as a way to approach and solve problems, being a concept used in theory and practice [3].

Design Thinking is a term used to describe how designers normally approach problem solving [13]. Starting with a holistic understanding of the problem, including customer needs (explicit and tacit), end user environment, social factors, market adjacencies and emerging trends, etc. Design Thinking is beyond the immediate limits of the problem to ensure that the right question is being addressed. Using interdisciplinary teams, Design Thinking incorporates diversity and leverages different paradigms and toolkits of each profession to analyze, synthesize and generate insight and new ideas. The interdisciplinary nature of Design Thinking also ensures that innovations are naturally balanced between the technical, commercial and human dimensions [13].

Design Thinking is a process of continually redesigning a business using insights derived from intimacy with the stakeholder. It is an approach that addresses product, process, and business model innovation to help project managers understand what features and skills are needed for implementation and how the process works, according to possible uncertainties that may exist. Learning only occurs when we move away from the familiar and accept the uncertainty that inevitably accompanies new experiences. Innovation means moving to uncertainty [14]. 
Beyond the domain of Design Thinking concepts and techniques, several authors cite the need to internalize the philosophy proposed by Design Thinking [3]. The conventional strategic model seeks incremental improvement, while in Design Thinking it is intended to rise a step in the design of products and services by means of a massive cultural change in the organizations that effectively place the client (in the case of this work, the DATASUS user) as the main actor of the process.

In order to achieve this goal, it is proposed to the Designers direct interaction with users, participating in their activities and experiencing their difficulties to provide insights, a key element of the Design Thinking that can not be obtained merely by the analysis of historical data. In this sense, Gobble [15] ratifies the need for human insight to make sense of Bigdata's techniques of quantitative analysis. Using another perspective, but not conflicting with those of Gobble, Liu et al [16] emphasize the need to give empirical value to innovation and to accept the uncertainties inherent in creating innovative solutions, making use of the scientific method of establishing premises and validating them through experimentation.

\subsection{Design Thinking in Requirements Elicitation}

As presented by [17], the requirements elicitation process with Design Thinking was divided into three phases, which are subdivided. The first phase is immersion where the data collection, analysis and synthesis are carried out. The second phase is ideation where the profile of an audience is defined, those that will be served by the creative solutions and, the innovative ideas. The third phase is prototyping where the captured reality is represented propitiating the validation of the proposed solution.

According to [18], the immersion process is called the staging process, where designers are instructed on what is relevant and what is irrelevant. During this phase, problem specification and constraints, idea reinterpretation, visualization, problem reshaping (including assessment and elaboration of situations) evolve. The immersion phase is subdivided into: proposing ideas, analyzing ideas, identifying ideas and organizing ideas, as shown in Figure 1

According to [19], the Immersion phase covers the analysis and synthesis of activities and involves a comprehensive understanding of the problem to be solved and part of superficial points to expressive points in terms of depth, subsidizes the application of solutions in contexts and serves as the basis for subsequent phases (ideation and prototyping). The process of ideation

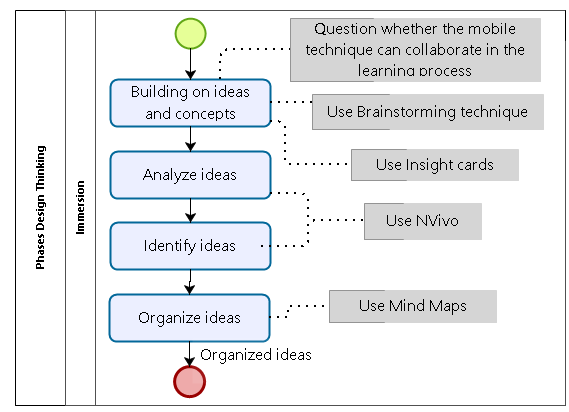

Figure 1. Immersion Subprocess [17].

is known as the assimilation process, which involves the proposed solution, data, and observations from the design environment [18]. The ideation phase is subdivided into: choose ideas, create profiles and raise requirements, as shown in Figure 2

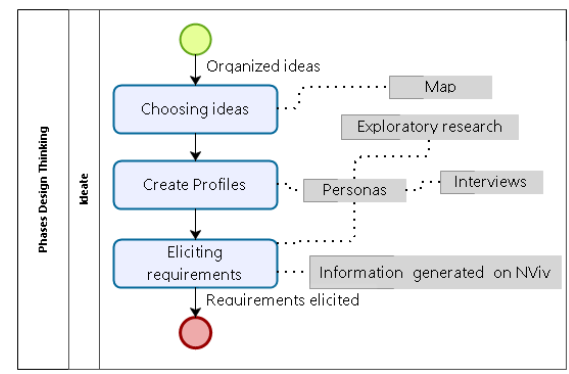

Figure 2. Ideation Subprocess [17].

The prototyping phase is, in fact, when the abstraction made in the Ideation phase materializes about the hypotheses of solutions indicated as satisfactory to remedy or mitigate the users' problems. Thus, artifacts prototypes representing the products and services created to address the problems identified should be constructed [20]. The function of prototyping is to help in the validation of the ideas generated, namely, in the elicitation of the requirements with the user. This is the last phase of Design Thinking, but it can occur throughout the project simultaneously with the Immersion and Ideation phase [21].

According to Macedo et al. [22], fast prototyping is part of the idea conception process, since it transforms an idea into something tangible and sometimes into experimental models, allowing one to visualize the concept and create new solutions, validating the needs raised with the user, as shown in Figure 3 Hence, elicitation of requirements can be more effective and generate satisfaction from those involved in the process. 


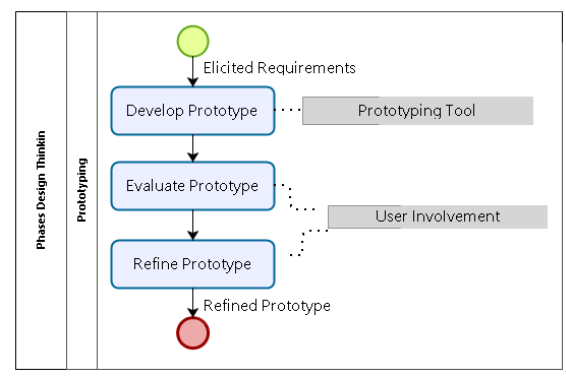

Figure 3. Prototype Subprocess [17].

\subsection{Knowledge Transfer in Development Process}

Knowledge transfer is a process in which knowledge is transferred from one person to another and may take place in a planned or natural manner as a result of another activity [23]. The knowledge transfer process entails the knowledge conversion into information, the information transfer, its interpretations, and the information conversion back to knowledge [24]. The work presented by Styczen et al. [25] defined a model for knowledge transfer in organizations that goes through a process to convert tacit knowledge into explicit knowledge and vice-versa. This knowledge conversion process is called a SECI (Socialization, Externalization, Combination, Internalization) spiral and has four knowledge conversion modes: Socialization, where the knowledge is transferred from tacit to tacit; Externalization, where the knowledge is transferred from tacit to explicit; Combination, where it is transferred from explicit to explicit; and Internalization, where it is transferred from explicit to tacit.

Knowledge generation is divided into two main subprocesses: knowledge creation and knowledge acquisition. Knowledge can either be generated through original knowledge that exists within the individuals in the organization, or knowledge can be acquired from external sources and integrated into the organization. Knowledge transfer is movement of knowledge from sender to receiver, understanding the knowledge transmitted and integrating it with existing knowledge within the receiver's mind [26].

The transfer of knowledge does not guarantee a full replication of the knowledge for the receiver. In fact, knowledge is often modified in the mind of the receiver [27]. Agile methods promote knowledge sharing through coordination, communication and collaboration between team members. Scrum advocates knowledge sharing through its four process activities: sprint planning, daily Scrum, sprint reviews and sprint retrospectives. Knowledge required for Agile software development is very context-dependent, and often it is difficult to transfer the context to different projects even within the same organization. Therefore, critically analyzing the knowledge before transfer is crucial for successful implementation of knowledge management systems. Knowledge transfer involves creation and acquisition of knowledge through several practices: project inception, stakeholder collaboration, formal training sessions, communities of practice and self-learning [28].

\section{Mobile Software Development Process}

To manage the development of mobile applications, DATASUS has formalized the Mobile Management and Development Process (PGDM). The PGDM is comprised of 5 stages: Initiation, Planning, Execution, Monitoring and Control, and Closing [29]. According to DATASUS [30], the purpose of the PGDM elaboration was to merge project management practices, according to the PMBOK [29], with good agile development practices, joining PMBOK processes and techniques with the agile development workflow [31]. The agile methodology adopted in PGDM is Scrum [32]. The premises of the work were: do not bureaucratize; do not over-document; do not carry out unnecessary processes; and do not add slowness to the team involved in the project. Figure 4 presents the phases of the Mobile Management and Development Process (PGDM) used in DATASUS.

The PGDM determines that, at the project initiation stage, stakeholder meetings should be held for a better understanding of the scope, timing, related strategic objectives, assumptions and constraints. In addition, studies of alternative solutions and feasibility analysis should be conducted. Specific rules or methodologies are not imposed for the requirements elicitation, and development teams are responsible for adopting the technique that they deem most appropriate. The adoption of Design Thinking in this phase is a choice of the development team.

The conduction of this study among the teams responsible for the requirements elicitation identified the use of the following techniques: working meetings with the requesting area of the project, interviews with managers and internal users of the Ministry of Health, participation in meetings of the National Council of Health Secretaries (CONASS) and the National Council of Municipal Health Secretaries (CONASEMS). These meetings produced the business requirements to be contemplated and implemented in the mobile application. The next stage of the PGDM 


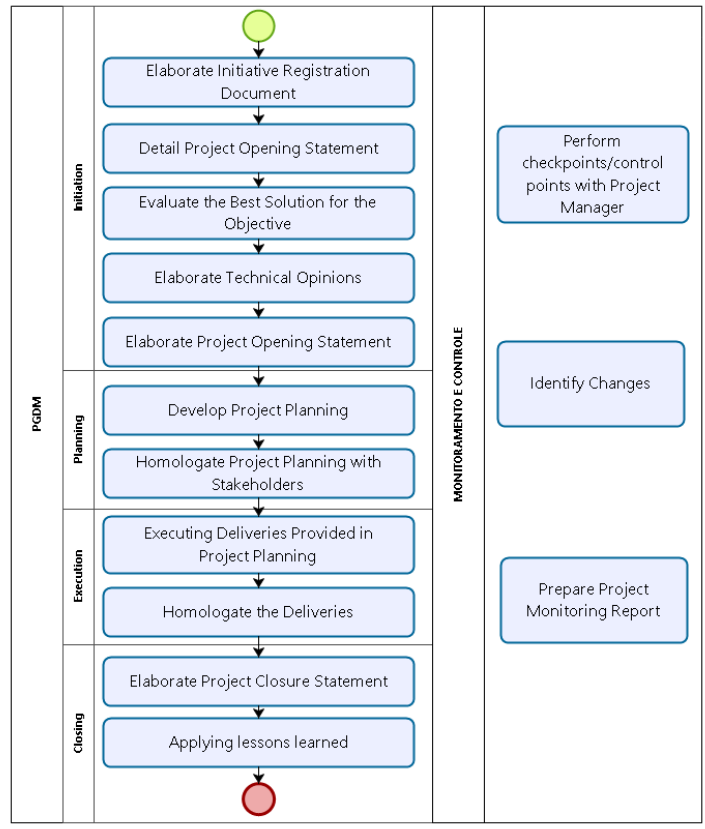

Figure 4. Phases of the Mobile Management and Development Process (PGDM) [30]

consists of the elaboration of a prototype for validation by the requesting area of the functional and usability aspects, and successive refinements are foreseen until there is consensus of the solution to be implemented, when then the product backlog and the sprint backlogs are defined [32]. The final Sprint delivery and acceptance of the project causes application distribution packages to be generated in both Google and Apple application stores.

To build the prototypes, the development team uses the Sketch [33] tool, which provides graphical editing capabilities for quick visual alternatives. The prototyping process is conducted jointly with usability analysts and with representatives from the requesting area. The prototypes are available for evaluation of other interested parties (all internal to the Agency), in a web environment, throughout the application life cycle. Figure 5 presents part of the screen of the application available in the site used to evaluate the prototypes. Each of these, when clicked/selected, allows navigation between the application screens. Four prototypes of mobile applications are shown in the figure, from left to right:

- E-Saúde (Blue) is aimed at users of the Unified Health System and offers access to personal and clinical information contained in the National Registry of Users of the Unified Health System, Citizen's Portal, Corporate and National Registry

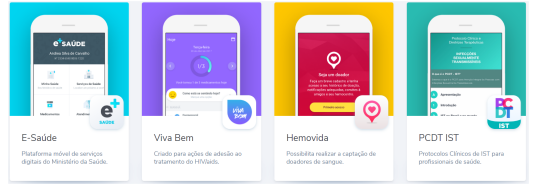

Figure 5. Prototype Validation Environment

of Health Establishment. Furthermore, for those enrolled in the National Transplantation System, it allows consultation to the position in which it is in the transplant queue.

- Viva Bem (Purple) is also targeted at SUS users and monitors withdrawals and take of antiretroviral drugs to improve adherence to Human Immunodeficiency Virus for users' use.

- Hemovida (Orange) is an application for the SUS user and has the purpose of capturing blood donors, supporting the blood centers of the Brazilian public health network to disseminate relevant information to the public and blood donation campaigns.

- PCDT IST (Green), or Clinical Protocol and Therapeutic Guidelines for Comprehensive Care for Persons with Sexually Transmitted Infections. The purpose of this application is to subsidize the medical conduct and facilitate the consultation by the health professionals to the guidelines of the protocols and guidelines related to the subject.

The monitoring of the applications offered is not restricted to the number of installations, versions in use and number of accesses. There is also a systematic follow-up of the comments posted on social networks and in the application stores, in search of demands for improvements made by users of the applications.

\section{Research Methodology}

In this work, we performed data collection through interviews with DATASUS managers, who are responsible for conducting the mobile development process. Our objective with these interviews was to identify the guidelines adopted for the process, as well as the priority elements considered in the requirements elicitation. Thus, it was sought to know the presence of characteristics adherent to Design Thinking in the organizational culture of DATASUS. During the activities, we carried out interviews with project managers and requirements analysts involved in the development of mobile applications, from which we obtained information on the techniques adopted in the initiation phase foreseen in the PGDM. 
We interviewed 15 project managers. The interviews were conducted in a pilot format, aiming to assess the quality and length of the interview script. After these pilot-interviews, we revised the interview script (we removed some questions as well as inserted and improved others). This set of interviews were transcribed and analyzed; we conducted two more interviews. A third source of data came from participation in CONASS and CONASEMS meetings, which discuss, among other topics, the development priorities of information systems for SUS. The expectation was to verify some guidelines of development that involved greater participation of the applications end users.

Finally, we carried out a detailed study of PGDM, in order to better understand its phases, trying to compare the phases related to the requirements elicitation to the adoption models of Design Thinking. At the end of each of these phases, we made a comparison with the phases and techniques recommended by Design Thinking, in order to verify the degree of adherence of the PGDM to the Design Thinking. Figure 6 presents our adopted methodology for conducting this study. The phases adopted were: 1 . Literature review of concepts and models of Design Thinking; 2. Interviews with managers and developers involved in the development process; 3. Analysis of the notes/observations made during the meetings between DATASUS, CONASS and CONASEMS; 4. Study of the mobile development process of the Ministry to understand its phases and characteristics; 5. Comparison between the phases of the PGDM and the phases of the Design Thinking model.

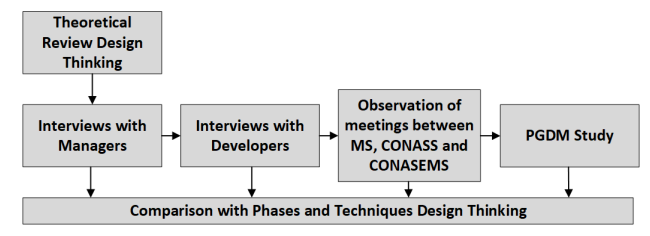

Figure 6. Methodology Adopted in the Elaboration of this Work

\section{Discussions and Results}

\subsection{RQ.1 What is the degree of adherence between the requirements elicitation process for DATASUS mobile applications and Design Thinking?}

In DATASUS, the development of mobile applications adopts the Brainstorming technique in the initial meetings with the requesting area of the project, serving to capture, in addition to the business rules, ideas about the presentation and operation of the application to be built. The same occurs in the interviews with managers and internal users of MS. On the other hand, participation in CONASS and CONASEMS meetings serves only to define aspects of governance to be followed, given the political nature of these meetings. Such activities are foreseen in Design Thinking, but are far from being considered user-centered. Design Thinking is centered on the human being who will make use of the product or service, not those involved with the creative organization. Therefore, these practices can not be considered as being adherent to Design Thinking.

The prototype evaluation and the version homologation do not involve end users either. What appears to be the practice closest to Design Thinking is the evaluation of the feedback posted on social media and in the application stores by citizens when specifying requirements for new versions. In the Table 1 is presented a comparison between the characteristics of the design elicitation phase of Design Thinking and the PGDM adopted in the Ministry.

Regarding the phases presented in [17], for a requirements elicitation in the Design Thinking format, it is not possible, if superficially, to establish a relation between them and the phases of the PGDM, which follows the route proposed by the PMBOK [29]. The Figure 7 establishes the identified relationship between the phases of Design Thinking and the PGDM. Therefore, this work is not intended to discuss the stages after the requirements elicitation phase, such as development and deployment. Although some

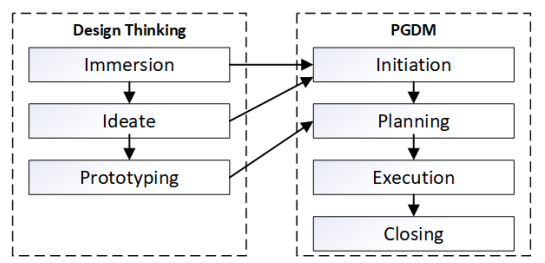

Figure 7. Comparison between the Design Thinking and PGDM phases

of the techniques proposed by Design Thinking are practiced in the process of development adopted by DATASUS, it is perceived in the PGDM, the bureaucratic bias characteristic of public agencies, evidencing a political-administrative orientation, to the detriment of the real needs of the SUS user population, which, if eventually (and partially) met, occurs either casually or because they are too obvious, rather than resulting from a cultural change of public managers and developers. 
Table 1. Characteristics and Techniques of Design Thinking versus PGDM

\begin{tabular}{|l|l|l|}
\hline Characteristic/Technique & Design Thinking & PGDM \\
\hline Brainstorming & Strong user interaction & No interaction with end users \\
\hline Insights & Strong user participation & Only from internal teams to MS \\
\hline Centered in & User & Process \\
\hline Focus & Creativity and innovation & Governance \\
\hline Validation of the prototype & By the user & By internal teams to MS \\
\hline
\end{tabular}

This finding corroborates the elicitation of the mobile applications destined to SUS users, presented in the Table 2. Although the SUS serves more than 60 million Brazilians, and the dissemination of these solutions in health care facilities, the number of mobile applications installations corresponds to only $1.5 \%$ of the total potential users. Users' evaluation, which is below the expectation of the Ministry's managers, is another indicator of low user satisfaction with the solutions offered, characterizing the lack of perception by the users that the solutions offered are relevant in their daily life. This lack of awareness can occur due to an unfriendly interface of these applications and a requirements elicitation without citizen participation.

The applications analyzed in this study were only those addressed to the citizen, those focused on administrative activities were not considered. The evaluated applications were:

Table 2. Demonstration of Installations and Evaluations of Applications Developed by DATASUS. Source: DATASUS Internal Management Reports.

\begin{tabular}{|l|r|c|c|}
\hline \multicolumn{1}{|c|}{ Application } & Downloads & $\begin{array}{c}\text { Users } \\
\text { / month }\end{array}$ & Avaliation \\
\hline Meu digiSUS & 918.094 & 162.838 & 4,0 \\
\hline Hemovida & 686 & 256 & 4,2 \\
\hline Viva Bem & 7.620 & 1.347 & 3,0 \\
\hline
\end{tabular}

- Meu digiSUS: new official mobile and digital service platform of the Ministry of Health, in which citizens have access to their main health information.

- Hemovida: The application aims to assist in capturing blood donors by supporting blood centers to disseminate information and blood donation campaigns to citizens.

- Viva Bem: This application alerts the user about their daily medications, dates and times of exams and vaccines.

One aspect considered positive in this work is the absence of impediments to the insertion of the concepts and practices of Design Thinking in the phases of initiation and planning of the PGDM, which allows its gradual introduction to the other phases, as the teams involved in the Design Thinking methodology. This adoption of the methodology may provide gains in relation to citizen participation, in the construction of applications with user-friendly interfaces, increase the adherence of its use, engage new users and meet the needs of dissemination of information from the Ministry.

\subsection{RQ.2 Was the transfer of knowledge between the software development teams using Design Thinking and the teams using the traditional process adequate and did it meet expectations?}

To answer this research question we considered the existence of two perspectives for the transfer of knowledge: 1. The perspective that occurs from the technical area proposing the application to the development team, with the intention of leveling the understanding of these teams regarding the functionalities and requirements of a business order; 2 . The perspective that occurs from the development team to DATASUS, seeking to subsidize improvements and evolutions in the developed application. The PGDM was designed to meet both perspectives, determining, in each of its phases, the delivery of specific artifacts, which are:

- Initiation

- Initiative Registration Document: records the initial demand for the requesting area, as well as the justification of the need and the objectives to be achieved.

- Technical Evaluation Document: records the technical feasibility analysis of the project. This document is prepared by DATASUS.

- Product Backlog: Registers the initially defined product backlog for the project. This document is prepared jointly by the requesting and technical areas.

- Planning 
Table 3. PGDM activities for knowledge transfer

\begin{tabular}{|c|c|c|c|}
\hline \multicolumn{4}{|c|}{ SECI Cycle } \\
\hline Socialization & Externalization & Combination & Internalization \\
\hline \multicolumn{4}{|l|}{ Initiation } \\
\hline $\begin{array}{l}\text { 1. Product Owner (PO) and } \\
\text { DATASUS interact to equate } \\
\text { the understanding of the } \\
\text { functionalities and business } \\
\text { requirements. }\end{array}$ & $\begin{array}{l}\text { 2. PO and DATASUS } \\
\text { prepare the Initiative } \\
\text { Master Document and the } \\
\text { Product Backlog. }\end{array}$ & $\begin{array}{l}3 . \text { DATASUS } \\
\text { registers the Technical } \\
\text { Assessment Document } \\
\text { in the project portfolio }\end{array}$ & $\begin{array}{l}\text { 4. The Scrum team } \\
\text { takes note of the } \\
\text { project and notes its } \\
\text { main doubts. }\end{array}$ \\
\hline \multicolumn{4}{|l|}{ Planning } \\
\hline $\begin{array}{l}\text { 5. The Scrum team holds } \\
\text { meetings to discuss the } \\
\text { technical and business aspects } \\
\text { of the application, developing a } \\
\text { non-functional prototype. }\end{array}$ & $\begin{array}{l}\text { 6. Based on activity 5, } \\
\text { PO and DATASUS update } \\
\text { the Initiative Master } \\
\text { Document and Product } \\
\text { Backlog. }\end{array}$ & $\begin{array}{l}\text { 7. DATASUS elaborates } \\
\text { the Project Charter } \\
\text { and the Architectural } \\
\text { Solution Document. }\end{array}$ & $\begin{array}{l}8 . \quad \text { The Scrum } \\
\text { team evaluates } \\
\text { implementation } \\
\text { alternatives, } \\
\text { beginning to practice } \\
\text { knowledge. }\end{array}$ \\
\hline \multicolumn{4}{|l|}{ Execution } \\
\hline $\begin{array}{l}\text { 9. PO and Scrum team interact } \\
\text { during sprints for refinement of } \\
\text { user stories and sprint backlog. }\end{array}$ & $\begin{array}{l}\text { 10. PO and Scrum team } \\
\text { build the test scenarios, } \\
\text { based on user stories. }\end{array}$ & $\begin{array}{l}\text { 11. DATASUS makes } \\
\text { a version of the source } \\
\text { code and registers the } \\
\text { Homologation Term. }\end{array}$ & $\begin{array}{l}\text { 12. At each iteration, } \\
\text { the Scrum team } \\
\text { studies the user } \\
\text { stories and notes the } \\
\text { issues for discussion } \\
\text { with the PO. }\end{array}$ \\
\hline \multicolumn{4}{|l|}{ Monitoring and Control } \\
\hline $\begin{array}{l}\text { 13. PO and Scrum team discuss } \\
\text { changes in the project, due } \\
\text { to administrative, technical or } \\
\text { political motivation. }\end{array}$ & $\begin{array}{l}\text { 14. PO and DATASUS } \\
\text { prepare the Request for } \\
\text { Change. }\end{array}$ & $\begin{array}{l}\text { 15. DATASUS records } \\
\text { the activities in the } \\
\text { Project Monitoring } \\
\text { Report. }\end{array}$ & $\begin{array}{l}\text { 16. The Scrum team } \\
\text { notes opportunities } \\
\text { for improvement } \\
\text { in the process or } \\
\text { project. }\end{array}$ \\
\hline \multicolumn{4}{|l|}{ Closing } \\
\hline- & $\begin{array}{l}\text { 17. PO and DATASUS } \\
\text { prepare the Project Closing } \\
\text { Statement. }\end{array}$ & $\begin{array}{l}\text { 18. DATASUS records } \\
\text { the lessons learned in the } \\
\text { knowledge base. }\end{array}$ & - \\
\hline
\end{tabular}

- Project Charter: formalizes the opening of the project for the application development, in the molds advocated by the PMBOK [29].

- Non-Functional Prototype: presents the functional characteristics to be incorporated into the application, in a representation of low-fidelity (wireframe) design.

- Architectural Solution Document: records the architectural decisions that will be followed in the implementation phase of the application.

\section{- Execution}

- Sprint Backlog: each sprint of the development process is elaborated the sprint backlog based on the revised product backlog.
- Navigable prototype: refinement of the non-functional prototype produced in the planning phase, adding navigation to the features contained in the sprint backlog, generating an average fidelity design representation for high (mockup).

- Test Scenarios: record the tests to be applied by the DATASUS team for acceptance of the version produced in the sprint.

- Source code of the version produced in the sprint.

- Evidence of Test: record the results obtained by applying the test scenarios.

- Homologation Term: formalizes the acceptance of the version produced in the sprint.

- Monitoring and Control 
- Change Request: describes and justifies the changes requested and made in planning artifacts, resulting from changes in scope or architecture.

- Project Follow-up Report: details the occurrences verified throughout the process, both ordinary and those that were not initially foreseen.

- Closing

- Project Closing Term: formalizes project closing and final application acceptance.

- Lessons Learned: records the treatment of the situations observed throughout the project, which allow the increase of the team maturity and the work processes, as well as the quality of the products generated.

The Table 3 presents the PGDM activities with the activities of the SECI Cycle, detailing the expected deliverables and the role they play for the transfer of knowledge. It is important to note that the artifact models and activities performed comply with the Brazilian legislation on software documentation developed by outsourced companies and guarantee DATASUS's ability to make corrections and evolutions, both by its internal team and by other companies, than the original developer (contracted company) of the application. The study therefore found that the activities and documentation involved in the transfer of knowledge meet the legal and regulatory requirements, and are effective for driving developments in applications developed by other teams.

\section{Limitations and Threats to Validity}

Our study is limited by the number of project managers that participated in our study. Although we conducted 2 interviews with 15 participants, we still believe our findings might not easily generalize. Moreover, the findings of this study are limited to the interviews conducted in the organization studied where our participants work. The perceptions of other project managers that work on similar projects in other organizations are still unknown — which could lead to different findings - and were not explored. Thus, it is necessary to verify in other organizations if the adoption of Design Thinking has facilitated the requirements elicitation process.

Although enriched with some quantitative data regarding the size of the contributions performed, this work is mainly based on the interviews conducted. Therefore, it is limited to our understanding of what the participants said. To mitigate threats hidden in qualitative analysis, after we transcribed the interviews, we analyzed each interview in pairs, followed by conflict resolutions meetings. When needed, third research was involved in the conflict meeting to drive consensus.

\section{Conclusions}

The adoption of Design Thinking in the development of mobile applications by DATASUS is at an embryonic stage. The use of the Brainstorming and Feedback techniques by social networks and application stores is expected to be complemented by other practices advocated by Design Thinking, such as greater interaction among Unified Health System (SUS) users and those responsible for the development of ministry's applications.

This study found that there is a low degree of adherence between the Design Thinking phases and the requirements elicitation process for mobile applications in DATASUS. However, they are not mutually exclusive, meaning they can work together, seeking improvements in the PGDM currently adopted by the Ministry.

Future work may include experiments to gauge the effectiveness of Design Thinking in creating innovative solutions from the insertion of developers among potential users of public health applications, given that fewer than $20 \%$ of users who install applications actually use them. In other words, if the PGDM uses techniques derived from Design Thinking, working with a user focus, these numbers tend to increase. Furthermore, we also plan to conduct interviews with other project managers and developers, triangulating the findings of this and previous studies, to confirm or refute known findings in the literature.

\section{Acknowledgements}

This research work has the support of the Research Support Foundation of the Federal District (FAPDF) research grant $05 / 2018$.

\section{References}

[1] E. D. Canedo and R. P. da Costa, "The use of design thinking in agile software requirements survey: A case study," in HCI (18), vol. 10918 of Lecture Notes in Computer Science, pp. 642-657, Springer, 2018.

[2] J. Jia, X. Yang, R. Zhang, and X. Liu, "Understanding software developers' cognition in agile requirements engineering," Sci. Comput. Program., vol. 178, pp. 1-19, 2019.

[3] A. Shirish, I. Boughzala, and S. C. Srivastava, "Does technology enabled design-thinking influence digital innovation? an innovation affordance perspective," in 
HICSS, pp. 1-12, ScholarSpace / AIS Electronic Library (AISeL), 2019.

[4] W. K. Kelm, A. V. de Mello, and M. Bernardino, "The state of practice in requirements engineering in the development of mobile applications," in SBQS, pp. 210-219, ACM, 2018.

[5] M. Ochodek and S. Kopczynska, "Perceived importance of agile requirements engineering practices - A survey," Journal of Systems and Software, vol. 143, pp. 29-43, 2018.

[6] I. Inayat, S. S. Salim, S. Marczak, M. Daneva, and S. Shamshirband, "A systematic literature review on agile requirements engineering practices and challenges," Computers in Human Behavior, vol. 51, pp. 915-929, 2015.

[7] C. Pflügler, M. Wiesche, and H. Krcmar, "Subgroups in agile and traditional it project teams," in Proceedings of the 51st Hawaii International Conference on System Sciences, 2018.

[8] J. E. Mathieu, S. I. Tannenbaum, J. S. Donsbach, and G. M. Alliger, "A review and integration of team composition models: Moving toward a dynamic and temporal framework," Journal of Management, vol. 40, no. 1, pp. 130-160, 2014.

[9] C. R. Rupakheti, M. Hays, S. Mohan, S. Chenoweth, and A. Stouder, "On a pursuit for perfecting an undergraduate requirements engineering course," in Software Engineering Education and Training (CSEE\&T), 2017 IEEE 30th Conference on, pp. 97-106, IEEE, 2017.

[10] M. Brhel, H. Meth, A. Maedche, and K. Werder, "Exploring principles of user-centered agile software development: A literature review," Information and Software Technology, vol. 61, pp. 163-181, 2015.

[11] H. Alahyari, R. Berntsson-Svensson, and T. Gorschek, "A study of value in agile software development organizations," Journal of Systems and Software, vol. 125 , pp. $271-288,2017$.

[12] F. Engberts and H. Borgman, "Application of design thinking for service innovation: Current practices, expectations and adoption barriers," in Proceedings of the 51st Hawaii International Conference on System Sciences, 2018.

[13] R. dos Santos Braz, J. R. Merlin, D. de Freitas Guilhermino Trindade, C. E. Ribeiro, E. M. Sgarbi, and F. de Sordi Junior, "Design thinking and scrum in software requirements elicitation: A case study," in $\mathrm{HCI}$ (18), vol. 11583 of Lecture Notes in Computer Science, pp. 179-194, Springer, 2019.

[14] P. Jarusriboonchai, J. L. Meissner, N. B. Hansen, and B. A. M. Schouten, "Thinking outside the (tool) box: Exploring empowerment through the design and use of toolkits," in $C \& T$, pp. 317-322, ACM, 2019.

[15] M. M. Gobble, "Design thinking," Research-Technology Management, vol. 57, no. 3, pp. 59-62, 2014.

[16] E. D. Vos, X. Xin, M. Emmanouil, and W. Liu, "Make the future visible today!: A reflection on using design thinking and futures studies techniques to foster creativity," in CCHI, pp. 31-38, ACM, 2018.

[17] C. Souza and C. Silva, "Uso do design thinking na elicitação de requisitos de ambientes virtuais de aprendizagem móvel," in CIbSE, pp. 561-574, Curran Associates, 2014.
[18] A. Azemi, "Promoting innovation through systems thinking and systems design," in SysCon, pp. 1-3, IEEE, 2018.

[19] F. Dobrigkeit and D. de Paula, "Design thinking in practice: understanding manifestations of design thinking in software engineering," in ESEC/SIGSOFT FSE, pp. 1059-1069, ACM, 2019.

[20] A. T. Alves, A. M. Lima, E. de Oliveira Sales, and A. S. Jorge da Costa, "Relato da Aplicação da Metodologia Design Thinking no Projeto de um Software para Mobilidade Urbana," SBSI, 2014.

[21] I. S. Khayal, "A systems thinking approach to designing clinical models and healthcare services," Systems, vol. 7, no. 1, p. 18, 2019.

[22] M. A. Macedo, P. A. C. Miguel, and N. Casarotto Filho, "a Caracterização Do Design Thinking Como Um Modelo De Inovação," Review of Administration and Innovation - RAI, vol. 12, no. 3, p. 157, 2015.

[23] B. Cartaxo, G. Pinto, and S. Soares, "Towards a model to transfer knowledge from software engineering research to practice," Information \& Software Technology, vol. 97, pp. 80-82, 2018.

[24] L. Szász, M. Scherrer, P. Deflorin, K. Sevrani, B. Cico, A. Besimi, K. Vukatana, and B. Rácz, "The role of ict-based information systems in knowledge transfer within multinational companies," in $A P M S(1)$, vol. 513 of IFIP Advances in Information and Communication Technology, pp. 185-193, Springer, 2017.

[25] A. Kowalska-Styczen, K. Malarz, and K. Paradowski, "Searching for effective and efficient way of knowledge transfer within an organization," in ICAART (1), pp. 151-158, SciTePress, 2018.

[26] S. Mirzaee and A. Ghaffari, "Investigating the impact of information systems on knowledge sharing," $J$. Knowledge Management, vol. 22, no. 3, pp. 501-520, 2018.

[27] Y. Andriyani, R. Hoda, and R. Amor, "Understanding knowledge management in agile software development practice," in KSEM, vol. 10412 of Lecture Notes in Computer Science, pp. 195-207, Springer, 2017.

[28] M. F. D. Brito, R. M. da Costa Figueiredo, E. Venson, E. D. Canedo, and L. C. M. R. Júnior, "Knowledge transfer in a management process for outsourced agile software development," in HICSS, pp. 1-10, ScholarSpace / AIS Electronic Library (AISeL), 2017.

[29] K. H. Rose, "A guide to the project management body of knowledge (pmbok® guide)—fifth edition," Project management journal, vol. 44, no. 3, 2013.

[30] B. Ministério da Saúde, "Processo de gerenciamento e desenvolvimento mobile," http://datasus.saude.gov.br/menu-pag-sobre-a-mds, May 2018. Acessado em 01/05/2018.

[31] M. J. G. Rodriguez, V. R. Montequin, J. M. V. Baisera, and R. Suarez, "Comparing agile and traditional methodologies of project management for software engineering," Scientific Publications/University of Economics in Katowice, pp. 64-75, 2017.

[32] K. Schwaber and M. Beedle, Agile software development with Scrum, vol. 1. Prentice Hall Upper Saddle River, 2002.

[33] V. Wyser, "Sketch annotation tool," July 11 2013. US Patent App. 13/347,684. 